BIS

Working paper No. 36

\title{
ESTIMATION OF SPECULATIVE ATTACK MODELS: MEXICO YET AGAIN
}

by

William R. Melick

August 1996

BANK FOR INTERNATIONAL SETTLEMENTS

Monetary and Economic Department

BASLE 
BIS Working Papers are written by members of the Monetary and Economic Department of the Bank for International Settlements and published by the Bank. The papers are on subjects of topical interest and are technical in character. The views expressed in them are those of their authors and not necessarily the views of the BIS.

(C) Bank for International Settlements 1996

CH-4002 Basle, Switzerland

All rights reserved. Brief excerpts may be reproduced or translated provided the source is stated.

ISSN 1020-0959 


\title{
ESTIMATION OF SPECULATIVE ATTACK MODELS: MEXICO YET AGAIN
}

by

\author{
William R. Melick
}

August 1996

\begin{abstract}
An amalgamation of standard speculative attack models is applied to Mexican exchange rate regimes over the past twenty years. The paper develops the first simultaneous (non-iterative) estimator for speculative attack models. Particular attention is paid to the December 1994 devaluation of the peso. Estimation results for the recent devaluation are a disappointment, less so for earlier periods when the assumptions of the model are more appropriate.
\end{abstract}





\section{Contents}

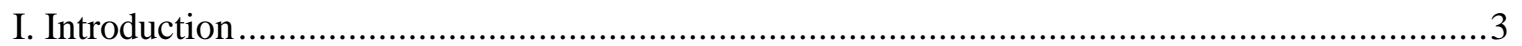

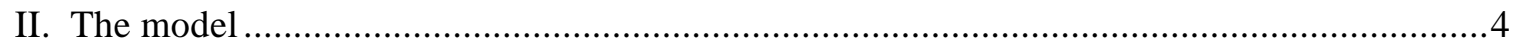

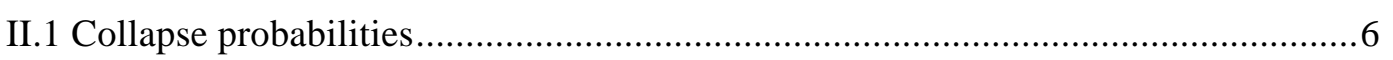

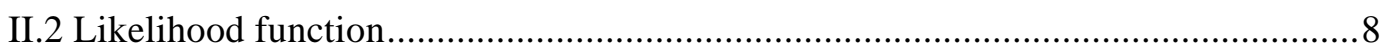

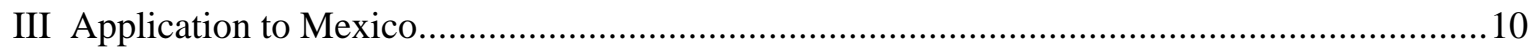

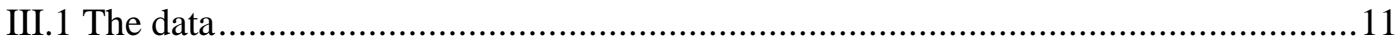

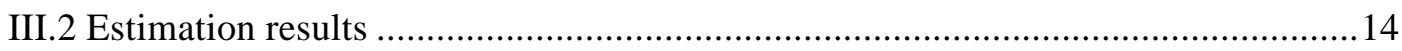

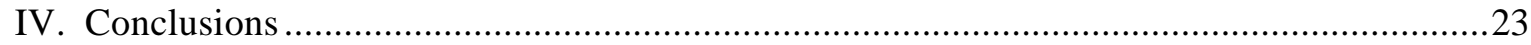

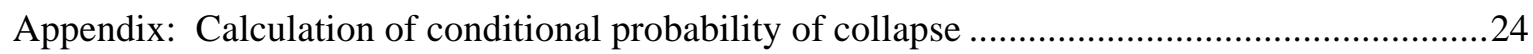

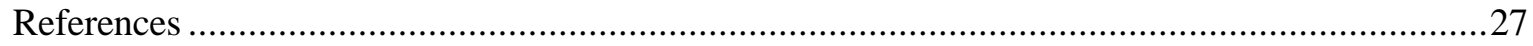





\section{Introduction ${ }^{1}$}

The floating of the Mexican peso in December 1994 renewed interest in the insights offered by theoretical models of speculative attacks on exchange rate regimes. In particular, is it possible to empirically implement one of the speculative attack models to provide an "early warning" of regime fragility? Although relatively few in number, existing applications of the speculative attack models offer some chance for useful predictive performance (see Blanco and Garber (1986) and Goldberg (1994) for applications to Mexico). This paper assesses the predictions from a standard speculative attack model, using the recent floating of the Mexican peso as a test case.

From the outset it is important to realize that the recent Mexican experience differs in several important respects from the highly stylized situation modelled in the speculative attack literature. First, in most speculative attack models the government is pursuing an expansionary fiscal policy, forcing rapid domestic credit creation that is eventually inconsistent with the fixed exchange rate regime. ${ }^{2}$ Market participants realize this inconsistency and exhaust the government's stock of international reserves at a moment such that the transition from a fixed to floating regime does not entail a discrete jump in the exchange rate. The recent Mexican experience was not characterised by such expansionary fiscal policy. ${ }^{3}$ Second, the speculative attack literature assumes that monetary authorities do not sterilise the loss of reserves at the time of the collapse, leading to a discrete jump in the money supply. This was not the case in Mexico, as pointed out by Folkerts-Landau and Ito (1995) and more formally by Flood, Garber and Kramer (1995). Third, the standard log linear speculative attack model does not allow domestic credit to become negative, although this is precisely what happened in Mexico to the domestic credit aggregate associated with the monetary base, the monetary aggregate most directly controlled by the Banco de Mexico. Therefore, arguably the most relevant measure of domestic credit cannot be used in the analysis, severely limiting the usefulness of any results. ${ }^{4}$ Finally, almost all of the speculative attack models are adaptations of the simple monetary model of exchange rate determination (see Obstfeld (1986a) and Penati and Pennachi (1989) for explicit optimisation models), so that these models miss elements such as a weakened banking sector and political instability that were important parts of the recent Mexican experience $.5,6$

1 Thanks to Greg Sutton for helpful discussion and Florence Béranger for helpful comments and research assistance.

2 The models of self-fulfilling (Obstfeld (1986b) and (1996)) and contagious speculative attacks (Gerlach and Smets (1994)) are not predicated on expansionary fiscal policy.

3 With the possible exception of the fiscal easing associated with the run-up to the presidential election in 1994.

4 This point is also discussed below. However, the measure of domestic credit used in the analysis does have the advantage that it includes the activities of the publicly-owned development banks. Credit creation by these institutions increased rapidly in 1993 and 1994 (see OECD (1995) and Dornbusch (1994)).

5 Perhaps for all of these reasons, the analysis of the recent Mexican experience by Ötker and Pazarbasiouglu (1995) uses a simple, unrestricted probit equation rather than a formal estimation of a speculative attack model. 
Despite all the above qualifications with regard to Mexico, it still remains an empirical question whether the speculative attack models can generate useful early warning signals. Mexico is an ideal country for estimating a speculative attack model, given its many regime changes over the past twenty years. Therefore, the paper proceeds with estimation for Mexico, providing some insight on early warning capabilities, and as a by-product offering the first simultaneous estimation of a speculative attack model. The remainder of the paper is organised as follows: Section II presents and solves a speculative attack model. Section III discusses the application to Mexico and presents estimation results. Conclusions are found in Section IV.

\section{The model}

We consider a relatively straightforward amalgamation of the monetary models of exchange rate determination used to study speculative attacks by Goldberg (1991), Flood and Hodrick (1986), and Flood and Garber (1984). ${ }^{7}$ The basic equations are:

$$
m_{t}^{d}-q_{t}=a_{0}-a_{1} i_{t}+a_{2} y_{t}-a_{3}\left(E_{t} s_{t+1}-s_{t}\right)
$$

$$
i_{t}=i_{t}^{*}+\left(E_{t} s_{t+1}-s_{t}\right)+\eta_{t}
$$

$$
q_{t}=\alpha p_{t}+(1-\alpha)\left(s_{t}+p_{t}{ }^{*}\right)
$$

$$
p_{t}=s_{t}+p_{t}^{*}+\delta_{t}
$$

$$
\delta_{t}=\rho \delta_{t-1}+\varepsilon_{t}
$$

$$
y_{t}=\beta\left(p_{t}^{*}+s_{t}-p_{t}\right)-\gamma\left(i_{t}-\left(E_{t} q_{t+1}-q_{t}\right)\right)
$$

$$
\Delta p_{t}^{*}=\Delta p_{t-1}^{*}+\tau\left(\pi^{*}-p_{t-1}^{*}\right)+\omega_{\mathrm{t}}
$$

$$
i_{t}^{*}=i_{t-1}^{*}+\kappa\left(i^{*}-i_{t-1}^{*}\right)+\psi_{t}
$$

6 See the recent work of Miller (1996) for a speculative attack model that incorporates domestic banking considerations.

7 A useful survey of the speculative attack literature is found in Agénor, Bhandari and Flood (1992). 


$$
M_{t}^{s} \equiv D_{t}+R_{t}
$$

$$
d_{t}=\mu+d_{t-1}+\theta_{t}
$$

with

$\begin{array}{lll}E & = & \text { expectations operator } \\ m^{d} & = & \text { natural logarithm of domestic money demand } \\ q & = & \text { natural logarithm of domestic price level } \\ i & = & \text { domestic interest rate } \\ y & = & \text { natural logarithm of domestic output } \\ s & = & \text { natural logarithm of the spot exchange rate } \\ & & \text { (domestic currency per unit of foreign currency) } \\ i^{*} & = & \text { foreign interest rate } \\ p & = & \text { natural logarithm of price index of domestically produced goods } \\ p^{*} & = & \text { level of domestic money supply } \\ M^{s} & = & \text { level of domestic credit } \\ D & = & \text { level of foreign reserves (valued in domestic currency) } \\ R & = & \text { natural logarithm of domestic credit } \\ d & = & \text { independently, normally distributed random variables } \\ \eta, \varepsilon, \omega, \psi, \theta & = & \text { autoregressive disturbance }\end{array}$

Equation (1) gives functional form to money demand, while equation (2) is the familiar uncovered interest parity condition with a time-varying risk premium. The level of domestic prices is determined according to equation (3), while equation (4) assumes that deviations from purchasing power parity follow a first-order auto regressive process. Output is demand determined, increasing in the relative price of foreign to home goods, and decreasing with increases in the real interest rate, as in equation (5). Equations (6) and (7) describe the evolution of foreign inflation and interest rates. Both variables mean revert around a long-run average level. The money supply is defined in equation (8) as the sum of domestic credit and reserves, while the process for domestic credit is specified in equation (9).

Under a fixed exchange rate, the above model can be solved for the level of reserves, after equating money supply to money demand. Under a floating regime, the level of the spot exchange rate can be solved for in the same fashion. However, in this case, the process by which expectations are formed must be specified. Throughout we will assume that expectations are formed rationally, that is that they are model consistent. 


\section{II.1 Collapse probabilities}

The central result of the collapsing exchange rate literature is that a collapse will occur whenever the floating rate that would be realised in the event of an attack $\left(\tilde{s}_{t}\right)$ is expected to be above the fixed exchange rate $\left(\bar{s}_{t}\right)$. This must be the case, since a speculator could earn expected profits at an infinite rate by buying the foreign currency at $\bar{s}_{t}$ just before the collapse and selling the foreign currency at $\tilde{S}_{t}$ just after the collapse. Arbitrage (the existence of other speculators) will eliminate the opportunity for these profits by driving $\tilde{S}_{t}$ to $\bar{S}_{t}$ at the time of the collapse. Put another way, the collapse will occur at such a time to eliminate any expected jump in the exchange rate in the transition from a fixed to floating regime.

In order to derive the collapse condition, it is necessary to first solve for $\tilde{s}_{t}$. This is done by rewriting equation (1), after substituting for $i_{t}, q_{t}$ and $p_{t}$, to yield

$$
\begin{aligned}
\tilde{s}_{t}= & \left(a_{1}+a_{3}\right)\left(E_{t} \tilde{s}_{t+1}-\tilde{s}_{t}\right)-\left(a_{0}+a_{2} \gamma \tau \pi^{*}\right)+m_{t}+\left(a_{1}+a_{2} \gamma\right) i_{t}^{*} \\
& -\left(a_{2} \gamma(1-\tau)+1\right) p_{t}^{*}+a_{2} \gamma(1-\tau) p_{t-1}^{*}+\left(a_{2}(\gamma \alpha(\rho-1)-\beta)+\alpha\right) \delta_{t} \\
& +\left(a_{1}+a_{2} \gamma\right) \eta_{t}
\end{aligned}
$$

The method of undetermined coefficients will be used to postulate a rational expectations solution for $\tilde{s}_{t}$. Naturally, the solution will involve the variables in equation (10), as well as their period $t+1$ expectations. Equations (6) and (7) will be used to replace $E_{t} i_{t+1}^{*}$ and $E_{t} p_{t+1}^{*}$ with functions of $i_{t}^{*}$ and $p_{t}^{*}$, but something must be done with $E_{t} m_{t+1}$. Towards this end, the approximation that $\ln (1+x) \cong x$ is used to rewrite equation (8) as ${ }^{8}$

$$
m_{t}^{s}=d_{t}+\frac{R_{t}}{D_{t}}
$$

In conjunction with equation (11), assuming that $\theta_{t}$ is normally distributed with mean zero and standard deviation $\sigma_{\theta}$ allows for the following calculation

$$
E_{t} m_{t+1}=m_{t}+\mu+\left(m_{t}-d_{t}\right)\left(e^{\frac{\sigma_{\theta}^{2}}{2}-\mu}-1\right)
$$

8 This approximation will lead to some estimation difficulties, as will be shown below. However, it is a solution to a problem that has plagued the speculative attack literature, namely, how to work with a model in log levels with a money supply definition in levels. Flood and Hodrick (1986) handle the problem with the unmotivated assumption that $m_{t}^{s}=w d_{t}+(1-w) r_{t}$. Goldberg (1991 and 1994) avoids the problem by specifying the entire model in levels. This leads to an unrealistic money demand function and creates difficulties in forming the rational expectations solution for the exchange rate. 
It is now possible to postulate an appropriate functional form for the method of undetermined coefficients

$$
\tilde{s}_{t}=\lambda_{0}+\lambda_{1} m_{t}+\lambda_{2} d_{t}+\lambda_{3} i_{t}^{*}+\lambda_{4} p_{t}^{*}+\lambda_{5} p_{t-1}^{*}+\lambda_{6} \delta_{t}+\lambda_{7} \eta_{t}
$$

Using equation (13) to solve for $E_{t} \tilde{s}_{t+1}-\tilde{s}_{t}$ and substituting this solution into equation (10) allows for solution of the undetermined coefficients.

$$
\begin{aligned}
& \lambda_{0}=\left(a_{1}+a_{3}\right)\left(\mu+\lambda_{3} \kappa i^{*}+\lambda_{4} \tau \pi^{*}\right)-\left(a_{0}+a_{2} \gamma \tau \pi^{*}\right) \\
& \lambda_{1}=\frac{1}{1-\left(a_{1}+a_{3}\right)\left(e^{\frac{\sigma_{\theta}^{2}}{2}-\mu}-1\right)} \\
& \lambda_{2}=1-\lambda_{1} \\
& \lambda_{3}=\frac{a_{1}+a_{2} \gamma}{1+\kappa\left(a_{1}+a_{3}\right)} \\
& \lambda_{4}=-\frac{a_{1}+a_{3}+a_{2} \gamma(1-\tau)+1}{1+\tau\left(a_{1}+a_{3}\right)} \\
& \lambda_{5}=-\left(1+\lambda_{4}\right) \\
& \lambda_{6}=-\frac{\alpha\left(1+a_{2} \gamma(\rho-1)\right)-a_{2} \beta}{1-\left(a_{1}+a_{3}\right)(\rho-1)} \\
& \lambda_{7}=\frac{a_{1}+a_{2} \gamma}{1+a_{1}+a_{3}}
\end{aligned}
$$

The unconditional probability (as of time $t-1$ ) of a collapse to a floating rate regime at time $t$ can then be calculated as

$$
\operatorname{Pr}_{t-1}\left[\tilde{s}_{t} \geq \bar{s}_{t}\right]=\operatorname{Pr}_{t-1}\left[\lambda_{0}+\lambda_{1} m_{t}+\lambda_{2} d_{t}+\lambda_{3} i_{t}^{*}+\lambda_{4} p_{t}^{*}+\lambda_{5} p_{t-1}^{*}+\lambda_{6} \delta_{t}+\lambda_{7} \eta_{t} \geq \bar{s}_{t}\right]
$$

using equations (4), (6), (7), (9) and (11) this condition may be re-written as

$$
\begin{aligned}
\operatorname{Pr}_{t-1} & {\left[\theta_{t}+\left(\frac{\lambda_{1} \bar{R}}{e^{\mu} D_{t-1}}\right) e^{-\theta_{t}}+\lambda_{3} \psi_{t}+\lambda_{4} \omega_{t}+\lambda_{6} \varepsilon_{t}+\lambda_{7} \eta_{t} \geq \bar{s}_{t}-H_{t-1}\right] } \\
H_{t-1} & =\left(\lambda_{0}+\lambda_{3} \kappa i^{*}+\lambda_{4} \tau \pi^{*}+\mu\right)+d_{t-1}+\lambda_{3}(1-\kappa) i_{t-1}^{*}-\left(1+\lambda_{6} \rho\right) p_{t-1}^{*} \\
& +\lambda_{4}(1-\tau) \Delta p_{t-1}^{*}+\lambda_{6} \rho p_{t-1}-\lambda_{6} \rho s_{t-1}
\end{aligned}
$$

where

At the time of a collapse, foreign reserves will be fixed at some level as authorities no longer intervene in the exchange market. This level is denoted above by $\bar{R}$. 


\section{II.2 Likelihood function}

Ideally, estimation of the structural parameters of the model and the probabilities of collapse should be done simultaneously. In earlier work this has not been done. Rather, Goldberg (1994), Cumby and Van Wijnbergen (1989), and Blanco and Garber (1986) have used either:

1) iterative procedures that estimate the money demand function and expected exchange rate depreciation (a probability weighted average of the fixed and shadow exchange rate) in turn until estimates of common parameters converge; or

2) OLS estimates from several structural equations to estimate the parameters needed to calculate devaluation probabilities.

Neither of these approaches is appealing, and in the case of Blanco and Garber requires an active futures market for the peso. A simultaneous estimation procedure can be straightforwardly (albeit tediously) constructed by first defining an indicator variable for a collapse ${ }^{9}$

$$
\begin{array}{r}
c_{t}=1 \text { if }\left[\theta_{t}+\left(\frac{\lambda_{1} \bar{R}}{e^{\mu} D_{t-1}}\right) e^{-\theta_{t}}+\lambda_{3} \psi_{t}+\lambda_{4} \omega_{t}+\lambda_{6} \varepsilon_{t}+\lambda_{7} \eta_{t} \geq \bar{s}_{t}-H_{t-1}\right] \\
=0 \text { if }\left[\theta_{t}+\left(\frac{\lambda_{1} \bar{R}}{e^{\mu} D_{t-1}}\right) e^{-\theta_{t}}+\lambda_{3} \psi_{t}+\lambda_{4} \omega_{t}+\lambda_{6} \varepsilon_{t}+\lambda_{7} \eta_{t}<\bar{s}_{t}-H_{t-1}\right]
\end{array}
$$

The likelihood of observing the realized random variables over the entire sample period $t=1$ to $T$ can then be written as

$$
\begin{aligned}
L= & \prod_{t=1}^{T} f_{\theta, \psi, \omega, a_{3}, \eta}\left[\theta_{t}, e^{-\theta_{t}}, \psi_{t}, \omega_{t}, a_{3} \eta_{t}\right] \\
& \quad \operatorname{Pr}\left[c_{t}=1 \mid \theta_{t}, e^{-\theta_{t}}, \psi_{t}, \omega_{t}, a_{3} \eta_{t}\right]^{c_{t}} \operatorname{Pr}\left[c_{t}=0 \mid \theta_{t}, e^{-\theta_{t}}, \psi_{t}, \omega_{t}, a_{3} \eta_{t}\right]^{\left(1-c_{t}\right)}
\end{aligned}
$$

where $f_{x}\left[x_{t}\right]$ denotes the density function for the random variable $x$. Notice that the probabilities of observing either $c_{t}=1$ or 0 are conditional on the errors from the other equations in model. Evaluation of the likelihood requires a specification for the joint density (the first term in the likelihood) as well as a specification for the conditional density that can be used to calculate the

9 The derivation of the likelihood follows Melick (1987). 
conditional probabilities that make up the remainder of the likelihood. Given the assumptions of independence and normality, the joint and conditional densities can be derived, except for a single complication. Notice that the use of the approximation in equation (11) has introduced a term involving the expression $\theta+b e^{-\theta}$ into the likelihood (where $b$ is some constant). Unfortunately, the transformation $z=\theta+b e^{-\theta}$ does not permit an explicit solution for $\theta$ in terms of $z$. This prevents the derivation of an analytical expression for the density function of $z .{ }^{10}$ Without such a density function, the likelihood cannot be evaluated. To proceed, the simplifying assumption that $\bar{R}=0$ is used, implying that the authorities will defend the regime until they run out of reserves. As can be seen by examining equation (16), this eliminates $e^{-\theta}$ from the likelihood, allowing it to be written as:

$$
\begin{aligned}
L= & \prod_{t=1}^{T} f_{\theta, \psi, \omega, a_{3} \eta}\left(\theta_{t}, \psi_{t}, \omega_{t}, a_{3} \eta_{t}\right) \cdot \operatorname{Pr}\left[c_{t}=1 \mid \theta_{t}, \psi_{t}, \omega_{t}, a_{3} \eta_{t}\right]^{c_{t}} \\
& \cdot \operatorname{Pr}\left[c_{t}=0 \mid \theta_{t}, \psi_{t}, \omega_{t}, a_{3} \eta_{t}\right]^{\left(1-c_{t}\right)}
\end{aligned}
$$

Invoking the independence of $\theta, \psi, \omega$, and $a_{3} \eta$, the natural logarithm of the likelihood becomes

$$
\begin{aligned}
\ln L=\sum^{T} & \ln f_{\theta}\left(\theta_{t}\right)+\ln f_{\psi}\left(\psi_{t}\right)+\ln f_{\omega}\left(\omega_{t}\right)+\ln f_{a_{3} \eta}\left(a_{3} \eta_{t}\right) \\
& \quad+c_{t} \ln \operatorname{Pr}\left[c_{t}=1 \mid \theta_{t}, \psi_{t}, \omega_{t}, a_{3} \eta_{t}\right]+\left(1-c_{t}\right) \ln \operatorname{Pr}\left[c_{t}=0 \mid \theta_{t}, \psi_{t}, \omega_{t}, a_{3} \eta_{t}\right]
\end{aligned}
$$

Using the change of variable technique, the conditional density for $c_{t}$ can be calculated. These details are left to the appendix. Denoting the standard normal probability density function and cumulative distribution function as $\phi$ and $\Phi$ respectively and using the results of the appendix, the log likelihood becomes

$$
\begin{aligned}
\ln L=\sum_{t=1}^{T} & \ln \left(\frac{1}{\sigma_{\theta}}\right)+\ln \phi\left(\frac{\theta_{t}}{\sigma_{\theta}}\right)+\ln \left(\frac{1}{\sigma_{\psi}}\right)+\ln \phi\left(\frac{\psi_{t}}{\sigma_{\psi}}\right)+\ln \left(\frac{1}{\sigma_{\omega}}\right)+\ln \phi\left(\frac{\omega_{t}}{\sigma_{\omega}}\right) \\
& +\ln \left(\frac{1}{a_{3} \sigma_{\eta}}\right)+\ln \phi\left(\frac{\eta_{t}}{\sigma_{\eta}}\right)+\ln \Phi\left[\left(\frac{\bar{s}_{t}-H_{t-1}-\lambda_{2} \theta_{t}-\lambda_{3} \psi_{t}-\lambda_{4} \omega_{t}-\lambda_{7} \eta_{t}}{\lambda_{6} \sigma_{\varepsilon}}\right)\left(1-2 c_{t}\right)\right]
\end{aligned}
$$

Using equations (1), (2), (6), (7), and (9) to substitute for $\theta_{t}, \psi_{t}, \omega_{t}$, and $\eta_{t}$ produces a likelihood written in terms of observables.

10 I have considered a MacLaurin series approximation to the function $z$. However, even a third order approximation does not appear to be very accurate. Moreover, writing $z$ as a third order polynomial in $\theta$ results in extremely complicated expressions for the joint and conditional densities that are needed to evaluate the likelihood function (equation (17)). 


$$
\begin{aligned}
\ln L=\sum_{t=1}^{T} & \ln \left(b_{1}\right)+\ln \phi\left(b_{1}\left(i^{*}+b_{2}+b_{3} i_{t-1}^{*}\right)\right)+\ln \left(b_{4}\right)+\ln \phi\left(b_{4}\left(m_{t}-q_{t}+b_{5}+b_{6} i_{t}+b_{7} y_{t}+b_{8} i_{t}^{*}\right)\right) \\
& +\ln \Phi\left[\left(b_{9}+b_{10} \bar{s}_{t-1}+b_{11} d_{t}+b_{12} d_{t-1}+b_{13} i_{t}^{*}+b_{14} p_{t-1}^{*}+b_{15} \Delta p_{t}^{*}+b_{16} p_{t-1}+b_{17} s_{t-1}\right.\right. \\
& \left.\left.+b_{18}\left(m_{t}-q_{t}\right)+b_{19} i_{t}+b_{20} y_{t}\right)\left(1-2 c_{t}\right)\right]+\ln \left(b_{21}\right)+\ln \phi\left(b_{21}\left(d_{t}+b_{22}-d_{t-1}\right)\right) \\
& +\ln \left(b_{23}\right)+\ln \phi\left(b_{23}\left(\Delta p_{t}^{*}+b_{24}+b_{25} \Delta p_{t-1}^{*}\right)\right)
\end{aligned}
$$

where (23)

$$
\begin{aligned}
& b_{1}=\frac{1}{\sigma_{\psi}} \\
& b_{2}=-k i^{*} \quad b_{3}=\kappa-1 \\
& b_{4}=\frac{1}{a_{3} \sigma_{\eta}} \\
& b_{5}=-a_{0} \\
& b_{6}=a_{1}+a_{3} \quad b_{7}=-a_{2} \quad b_{8}=-a_{3} \\
& b_{9}=\frac{-\left(\lambda_{0}-\left(1+\lambda_{2}\right) \mu-\frac{\lambda_{7} a_{0}}{a_{3}}\right)}{\lambda_{6} \sigma_{\varepsilon}} \quad b_{10}=\frac{1}{\lambda_{6} \sigma_{\varepsilon}} \\
& b_{11}=\frac{-\lambda_{2}}{\lambda_{6} \sigma_{\varepsilon}} \\
& b_{12}=\frac{-\left(1-\lambda_{2}\right)}{\lambda_{6} \sigma_{\varepsilon}} \\
& b_{13}=\frac{-\left(\lambda_{3}-\lambda_{7}\right)}{\lambda_{6} \sigma_{\varepsilon}} \quad b_{14}=\frac{1+\lambda_{6} \rho}{\lambda_{6} \sigma_{\varepsilon}} \\
& b_{15}=\frac{-\lambda_{4}}{\lambda_{6} \sigma_{\varepsilon}} \\
& b_{16}=\frac{-\lambda_{6} \rho}{\lambda_{6} \sigma_{\varepsilon}} \\
& b_{17}=\frac{\lambda_{6} \rho}{\lambda_{6} \sigma_{\varepsilon}} \\
& b_{18}=\frac{-\lambda_{7} / a_{3}}{\lambda_{6} \sigma_{\varepsilon}} \\
& b_{19}=\frac{-\lambda_{7}\left(a_{1}+a_{3}\right) / a_{3}}{\lambda_{6} \sigma_{\varepsilon}} \\
& b_{20}=\frac{\lambda_{7} a_{2} / a_{3}}{\lambda_{6} \sigma_{\varepsilon}} \\
& b_{21}=\frac{1}{\sigma_{\theta}} \\
& b_{22}=-\mu \\
& b_{23}=\frac{1}{\sigma_{\omega}} \\
& b_{24}=-\tau \pi^{*} \\
& b_{25}=\tau-1
\end{aligned}
$$

The log likelihood can be split into five pieces; four least squares estimations corresponding to equation (7), a combination of equations (1) and (2), equation (9) and equation (6), and a probit estimation. Ignoring parameter restrictions, these pieces could be estimated in isolation. However, amongst the parameters there are the following six restrictions:

$$
\begin{array}{lll}
b_{12}=-\left(b_{10}+b_{11}\right) & b_{16}=b_{10}-b_{14} & b_{17}=-b_{16} \\
b_{18}=\frac{b_{12}\left(1+b_{6}\left(1+b_{3}\right)\right)}{b_{8}\left(1-\left(1+b_{6}\right)\right)} & b_{19}=b_{18} \cdot b_{6} & b_{20}=b_{18} \cdot b_{7}
\end{array}
$$

These restrictions force the likelihood to be maximised jointly.

\section{Application to Mexico}

There is considerable interest in whether the floating of the Mexican peso in December 1994 was predictable. Moreover, prior to December 1994, Mexico had a long history of essentially 
fixed exchange rate regimes, with many changes to the fixed rate parity since 1976 . Therefore Mexico is an ideal country for estimating the model derived in Section II, offering sufficient variation in $c_{t}$.

\section{III.1 The data}

For reasons of data availability, the estimations cover the period 1975 through 1994 at a monthly frequency. Table 1 lists the dates of the Mexican exchange regime collapses during this period, with collapse defined as either a devaluation or a switch to a more flexible regime (for example an increase in the rate of a crawling peg).

Table 1

Mexican exchange rate regime collapses

\begin{tabular}{|l|l|}
\hline \multicolumn{1}{|c|}{ Date } & \multicolumn{1}{|c|}{ Collapse } \\
\hline 1st September 1976 & 39\% devaluation from 12.5 to 20.5 pesos per US dollar \\
\hline 19th February 1982 & $\begin{array}{l}\text { Floating of the peso, crawling peg with crawl rate of 0.04 pesos per day established } \\
\text { 5th June 1982 }\end{array}$ \\
\hline 13th August 1982 & $\begin{array}{l}\text { Exchange market closed, floating of peso for remainder of August, peso fixed at 50 } \\
\text { beginning 1st September 1982 }\end{array}$ \\
\hline 20th December 1982 & 47\% devaluation, crawling peg with crawl rate of 0.13 pesos per day \\
\hline 6th December 1984 & Increase in rate of crawl to 0.17 pesos per day \\
\hline 6th March 1985 & Increase in rate of crawl to 0.21 pesos per day \\
\hline 25th July 1985 & $\begin{array}{l}\text { 17\% devaluation, continuation of crawling peg with crawl rate of 0.21 pesos per } \\
\text { day }\end{array}$ \\
\hline 18th November 1987 & $\begin{array}{l}\text { Floating of the peso, fixed at 2,209.7 on 14th December 1987, 2,281 on 1st March } \\
1988\end{array}$ \\
\hline 1st January 1989 & $\begin{array}{l}\text { Crawling peg, 1 peso per day. Rate of crawl reduced to 0.8 per day on 28th May } \\
1990, \text { to 0.4 per day on 13th November 1990 and to 0.2 per day on 12th November } \\
1991\end{array}$ \\
\hline 22nd October 1992 & Rate of crawl increased to 0.4 per day \\
\hline 20th December 1994 & Peso devalued, floated on 22nd December 1994 \\
\hline
\end{tabular}

Sources: IMF Annual Report of Exchange Rate Arrangements and Exchange Restrictions (various issues), and Ötker and Pazarbasioglu (1994), Table 1.

Identifying the appropriate time series that correspond as closely as possible to the theoretical constructs of the model in Section II is not entirely straightforward. This is especially true for the money supply $(m)$ and domestic credit $(d)$. Ideally, the concept of base money recently targeted by the Banco de Mexico and its companion net domestic credit should serve as the empirical constructs for $m$ and $d .{ }^{11}$ However, the log-linear structure of the model does not allow for nonnegative variables, ruling out the use of these two series. As a second-best solution, alternate constructs of domestic credit and money were used. The advantage of this measure of domestic credit is that it includes credit extended by the development banks. Finally, the United States was treated as

11 See Banco de Mexico (1995) and Kamin and Rogers (1995) for detail on the desirability of the base money concept. 
the foreign country. The data series used for each variable in the model are listed in Table 2, with all data coming from the International Monetary Fund IFS data tape. Chart 1 plots the natural logarithms of the data. There are two features of the data worthy of mention. First, $\bar{s}$ is formally undefined during floating exchange rate periods, of which there were several between 1975 and 1994. During these periods a collapse is impossible, complicating any estimation across the full sample period. To circumvent this problem, $\bar{s}$ was defined to equal 999.999 new pesos per dollar, a value large enough to force the probability of a collapse to zero (see equation (16)). Second, an improvement in data collection procedures within Mexico produced a discontinuity in domestic credit in December 1977. This can clearly confound estimation and interpretation. Therefore, as discussed further in Section III.2, several estimation periods will be used.

Table 2

Data series: 1975:01 - 1994:12

\begin{tabular}{|c|c|}
\hline Variable & IFS Series \\
\hline$D$ - Domestic credit & Mexico - line 32 - monetary survey, domestic credit \\
\hline$R$ - Foreign reserves & Mexico - line 11 - monetary authority, foreign assets \\
\hline$M$ - Money supply & $\mathrm{D}+\mathrm{R}$ \\
\hline$P$ - Price index of domestically produced goods & Mexico - line 64 - consumer prices \\
\hline$Y$ - Output & Mexico - line 66 - industrial production \\
\hline$i$ - Interest rate ${ }^{*}$ & $\begin{array}{l}\text { Mexico - line 60c - Treasury bill rate } \\
\text { line 60n - average cost of funds } \\
\text { 60n from 1975:01-1979:12, 60c thereafter }\end{array}$ \\
\hline$S$ - Exchange rate & Mexico - line we - end-month \\
\hline $\bar{S}$ - Fixed exchange rate & Author's calculations - based on Table 1 \\
\hline$i^{*}-$ Foreign interest rate ${ }^{*}$ & United States - line 60c - Treasury bill rate \\
\hline$P^{*}-$ Foreign price index & Unites States - line 63 - producer prices \\
\hline$X$ - Exports & Mexico - line 90c - exports of goods and services \\
\hline$M$ - Imports & Mexico - line 98c - imports of goods and services \\
\hline$G D P$ - Gross domestic product & Mexico - line $99 \mathrm{~b}$ - gross domestic product \\
\hline$\alpha$ & $1-\frac{X+M}{G D P}$ \\
\hline$q$ - Natural logarithm of domestic price level & $\alpha p+(1-\alpha)\left(s+p^{*}\right)$ \\
\hline$c$ - Collapse dummy & $\begin{array}{l}\text { Equals } 1 \text { for months shown in column } 1 \text { of Table } 1,0 \\
\text { otherwise }\end{array}$ \\
\hline
\end{tabular}

* Converted from annual rates to monthly rates according to $i=\ln \left(1+\frac{\text { annualrate }}{12}\right)$. 
Chart 1

Data series 1975:01 - 1994:12
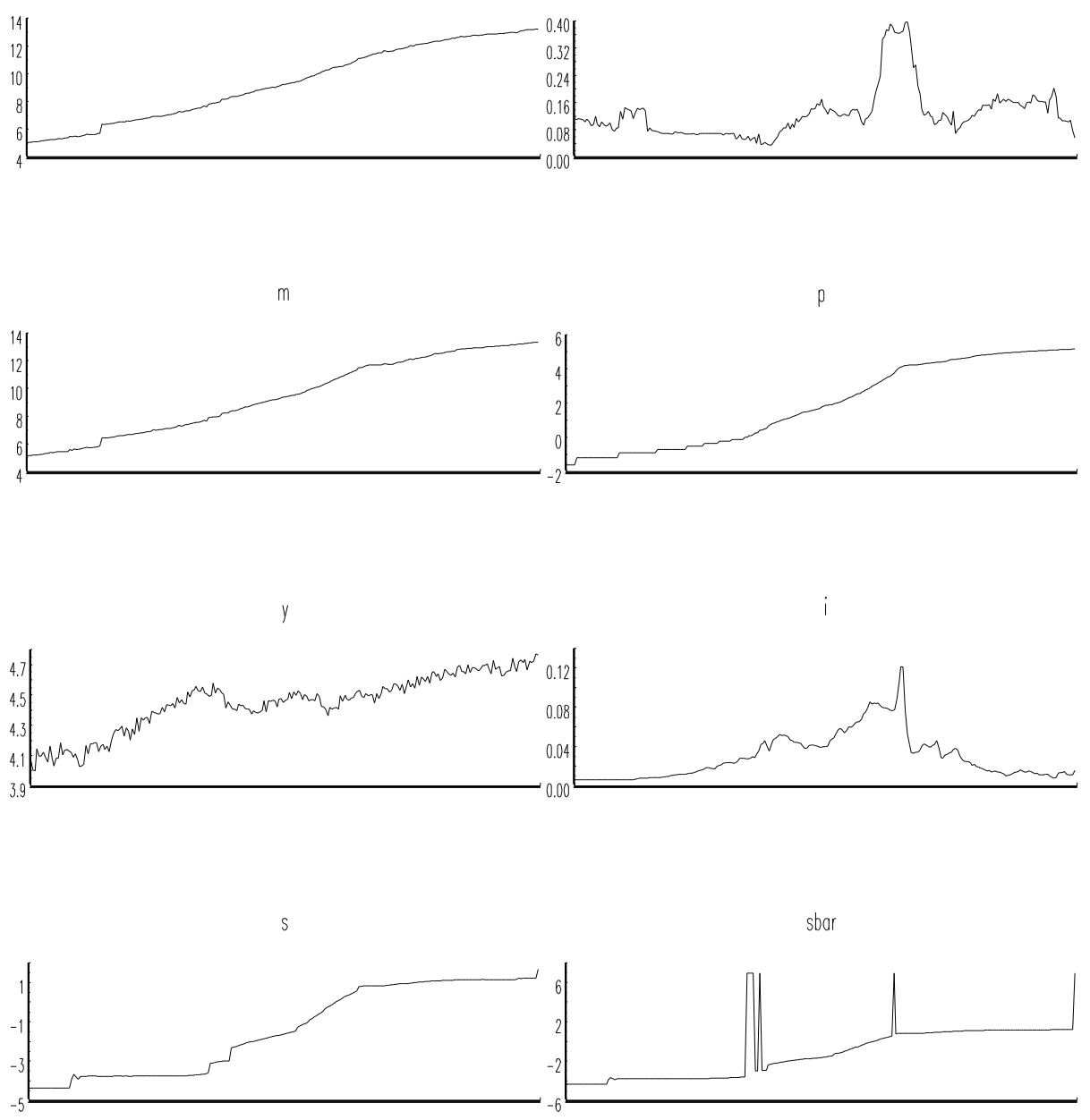

i*

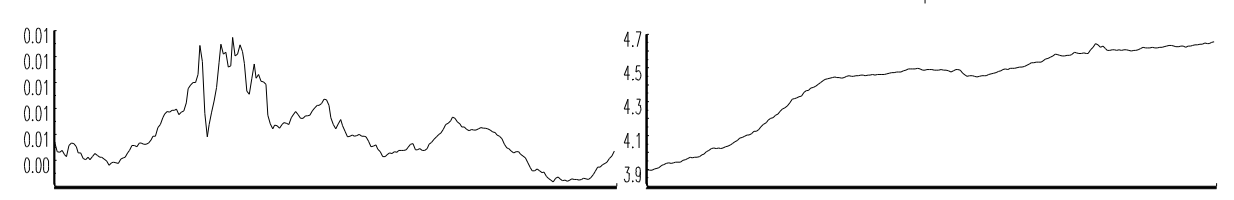




\section{III.2 Estimation results}

As noted above, the likelihood can be separated into five independent, easily estimated pieces when parameter restrictions are ignored. With the restrictions in place, the likelihood can be separated into two pieces, one involving parameters $b_{1}$ through $b_{20}$ and a second involving parameters $b_{21}$ through $b_{25}$. To ensure that the entire log likelihood was coded correctly, four OLS and one probit equation were estimated and compared to the unrestricted maximum likelihood results. For each parameter the results were identical. ${ }^{12}$ With the restrictions in place the two pieces were maximized independently to ease computational burdens. In all results reported below, estimation results are from the Constrained Maximum Likelihood (CML) application module for Gauss version 3.2.14.

Parameter estimates from both the unrestricted and restricted models are in Table 3, with the likelihood ratio test of the six restrictions also shown. As can be seen from equation (23), recovery of the structural parameters from the reduced form coefficients $\left(b_{1}-b_{20}\right)$ is not straightforward. Moreover, given the predictive nature of the exercise and the stylised model, the recovery is probably not worthwhile in most cases. However, a few of the structural parameters are easily obtained. Probably most interesting are the parameters from the money demand equation, equation (1). These results are disappointing, with the interest rate semi-elasticities having signs opposite that assumed by the model. Reduced form coefficient $b_{6}$, the sum of $a_{1}$ and $a_{3}$, is significantly negative instead of positive. Coefficient $b_{8}$, equal to $-a_{3}$, is significantly positive instead of negative. On the bright side, coefficient $b_{7}$, equal to $-a_{2}$ (the income elasticity), is positive, although implausibly large. Also of interest are the foreign target interest rate and inflation rate ( $i^{*}$ and $\pi^{*}$ respectively) from equations (6) and (7). Reduced form coefficients in Table 3 imply that the US Treasury bill rate mean-reverted around an annual rate of 7.0 percent, with 2.5 percent adjustment per month whenever away from this rate. Corresponding figures for the US inflation rate are mean reversion around an annual rate of 3.8 percent, with a much too large 52 percent adjustment per month toward this rate. In part, all of these negative results stem from the simplistic functional forms assumed in the model. Unfortunately, the use of more realistic functional forms would render the derivation of the likelihood function intractable. Finally, as can be seen at the bottom of Table 3, the restricted version of the model is soundly rejected.

More to the point of the predictive nature of the exercise, Chart 2 presents the withinsample fitted values (from both the restricted and unrestricted model) of the conditional collapse probabilities, along with the times of the actual collapses. These fitted values are calculated using equation (A8), that is using the actual values of the variables at time $t$ to generate estimates of $\hat{\theta}_{t}, \hat{\psi}_{t}, \hat{\omega}_{t}$ and $\hat{\eta}_{t}$. Especially for the unrestricted model, the probabilities correspond fairly closely to the actual collapse, although there are several false signals. In general the probabilities do not gradually increase prior to a collapse, but tend to shoot up as little as one month before the collapse.

12 Excepting the well-known $n$ versus $n-1$ difference between OLS and maximum likelihood estimates of standard errors. 
Table 3

Estimation results 1975:01-1994:12

\begin{tabular}{|c|c|c|c|c|}
\hline & \multicolumn{2}{|c|}{ Unrestricted } & \multicolumn{2}{|c|}{ Restricted } \\
\hline & Estimate & $\begin{array}{c}\text { Standard } \\
\text { error }\end{array}$ & Estimate & $\begin{array}{c}\text { Standard } \\
\text { error }\end{array}$ \\
\hline$b_{1}$ & 1804.848 & 82.3801 & 1804.847 & 82.3802 \\
\hline$b_{2}$ & -0.0001 & -- & -0.0001 & -- \\
\hline$b_{3}$ & -0.9745 & 0.0147 & -0.9745 & 0.0147 \\
\hline$b_{4}$ & 2.4394 & 0.1114 & 2.4394 & 0.1114 \\
\hline$b_{5}$ & 27.4127 & 0.6491 & 27.4129 & 0.6491 \\
\hline$b_{6}$ & -7.686 & 1.1529 & -7.6846 & 1.153 \\
\hline$b_{7}$ & -7.7299 & 0.1453 & -7.7299 & 0.1453 \\
\hline$b_{8}$ & 216.6002 & 10.9386 & 216.593 & 10.9386 \\
\hline$b_{9}$ & 50.0154 & 26.0603 & 4.4343 & 3.7443 \\
\hline$b_{10}$ & 28.011 & 28.8477 & 0.4195 & 0.4586 \\
\hline$b_{11}$ & -13.1204 & 5.1109 & -4.5868 & 1.6934 \\
\hline$b_{12}$ & 8.7892 & 3.2512 & 4.1673 & 1.6254 \\
\hline$b_{13}$ & 340.4162 & 195.8908 & -22.3534 & 61.2056 \\
\hline$b_{14}$ & -3.1499 & 6.4321 & 0.7045 & 0.7577 \\
\hline$b_{15}$ & -14.6134 & 34.9864 & 15.5879 & 28.5937 \\
\hline$b_{16}$ & -6.3385 & 2.7593 & -0.285 & 0.9918 \\
\hline$b_{17}$ & -21.0358 & 28.3918 & 0.285 & 0.9918 \\
\hline$b_{18}$ & 7.792 & 4.6594 & 0.0021 & 0.0009 \\
\hline$b_{19}$ & -50.9973 & 16.3634 & -0.0159 & 0.0066 \\
\hline$b_{20}$ & -3.9152 & 6.0727 & -0.016 & 0.0073 \\
\hline$b_{21}$ & 18.0901 & 0.8257 & 18.0901 & 0.8257 \\
\hline$b_{22}$ & -0.0342 & 0.0036 & -0.0342 & 0.0036 \\
\hline$b_{23}$ & 195.9609 & 8.9443 & 195.9609 & 8.9443 \\
\hline$b_{24}$ & -0.0016 & 0.0004 & -0.0016 & 0.0004 \\
\hline$b_{25}$ & -0.4809 & 0.0565 & -0.4809 & 0.0565 \\
\hline $\begin{array}{c}\text { Log } \\
\text { likelihood }\end{array}$ & \multicolumn{2}{|c|}{2582.927} & \multicolumn{2}{|c|}{2572.921} \\
\hline $\begin{array}{c}\text { Likelihood } \\
\text { ratio test }\end{array}$ & \multicolumn{4}{|c|}{20.012} \\
\hline P-value & \multicolumn{4}{|c|}{0.001} \\
\hline
\end{tabular}




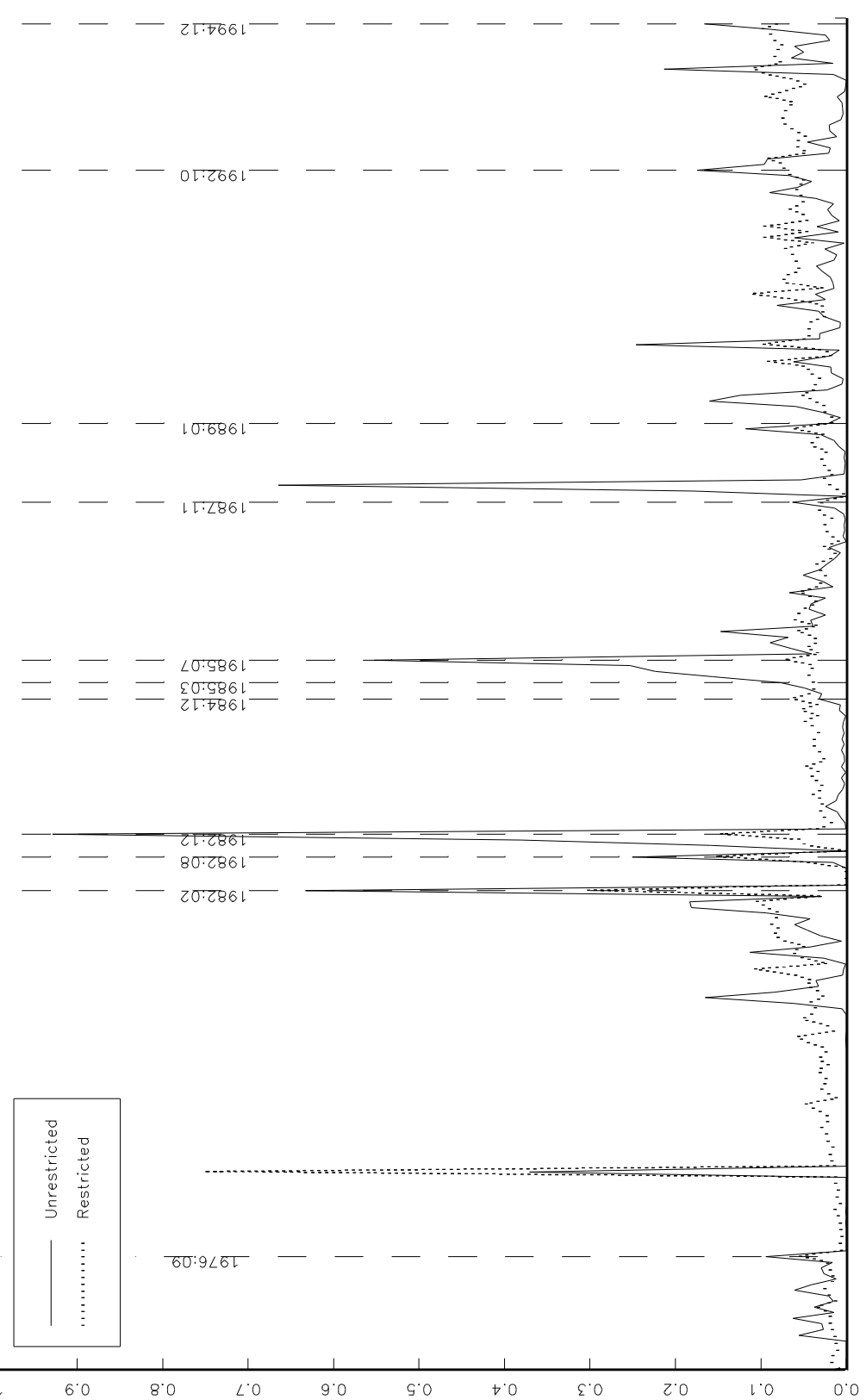




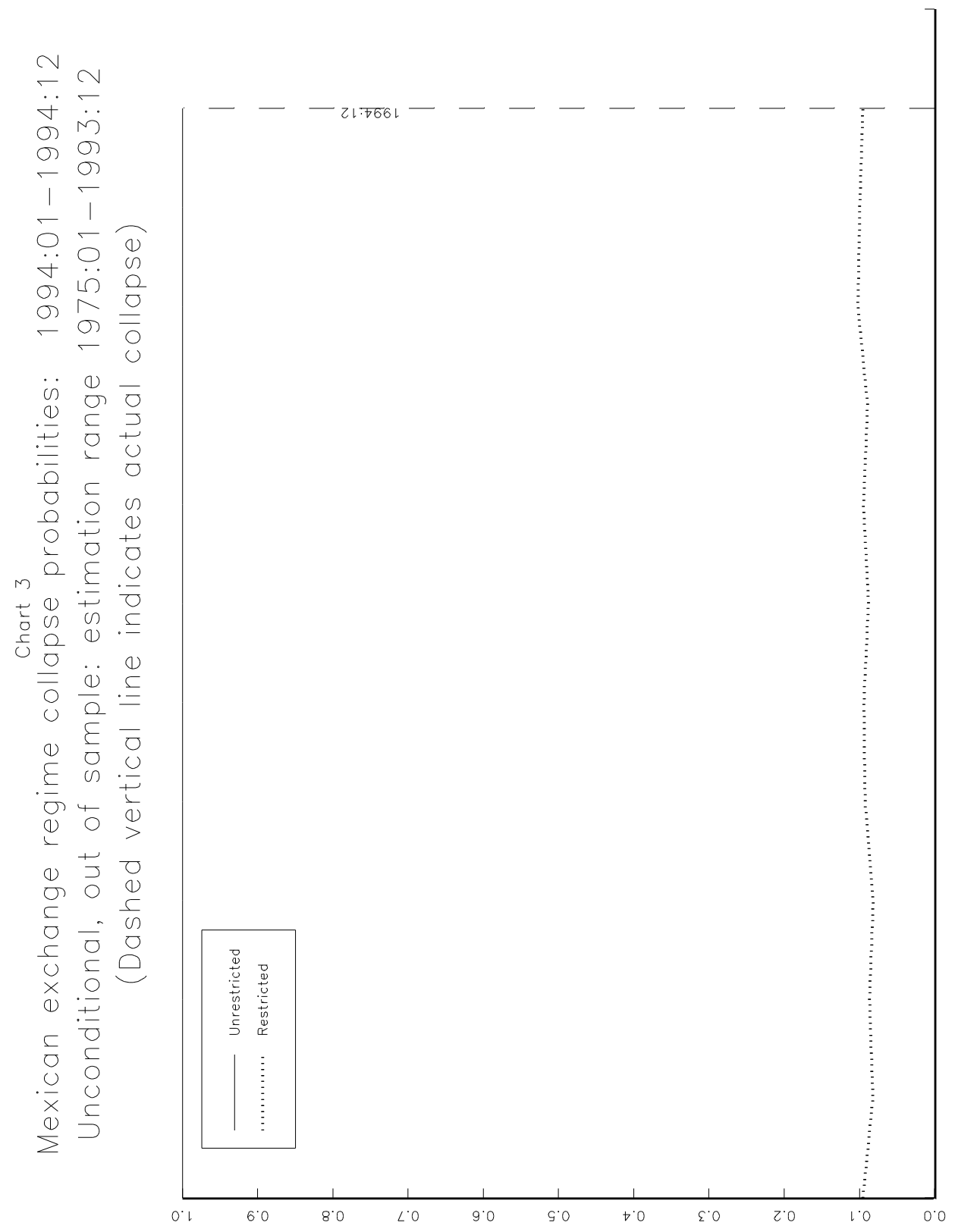


However, these are not the probabilities that could be calculated for ex ante monitoring purposes. In this situation, time $t$ values of the variables would not be available, only the unconditional time $t-1$ probabilities are relevant. Chart 3 displays true ex ante probabilities for the twelve months of 1994 calculated with parameters estimated using data from 1975:01 through 1993:12.13 The results are very disappointing. The unrestricted probability of a collapse is equal to one for each of the twelve months, while the restricted probabilities are basically flat at roughly .10 for each of the twelve months. Neither set of probabilities generates a reliable signal that could have served as an early warning indicator.

As mentioned above, the jump in domestic credit in December 1977 is troubling. In fact, the jump generates a spurious increase in collapse probability, as can be seen in Chart 2. To ensure that the above results are not sensitive to the discontinuity, the model is estimated over the shorter period 1978:01-1994:12. Results are found in Table 4 and Charts 4 and 5 that mimic in form Table 3 and Charts 1 and 2. Results are very close to those from the longer estimation period. Again, the main conclusion that the model does not generate a useful early warning indicator continues to hold.

Even though negative, the prediction results are not much worse than those found in earlier studies. Blanco and Garber (1986) present the most optimistic results. They calculate collapse probabilities for the period 1973 through 1982, with only the 1982 probabilities being out-of-sample. They find that collapse probabilities peaked at .2 prior to the 1976 collapse, tailing off rapidly after the devaluation. Probabilities then increased slowly through the end of 1981, peaking at just below .3 prior to the collapses in February and August of 1982. ${ }^{14}$ Goldberg's (1994) results are not as positive. The probabilities do not appear to peak before the collapses in late 1984 and 1985, and there are several false signals in 1986. In general, Goldberg's probabilities are much more "spiky", similar to those found in Charts 2 and 4.

Two factors may account for the relatively positive results of Blanco and Garber, the mildly negative findings of Goldberg and the negative findings of Charts 2-5. First, Blanco and Garber were able to make use of the futures market for pesos that was active over their estimation period. Access to an asset price that directly incorporates devaluation expectations will improve any estimation. Secondly, both Blanco and Garber and Goldberg examine periods which better fit the assumptions of the standard speculative attack model. A better case can be made that fiscal profligacy lay behind the collapses in the 1970s and 1980s than that of December 1994. Evidence of this second point can be found in Chart 6. Here, collapse probabilities are calculated for 1984 and 1985, estimating the model through 1983. The restricted probabilities form a smooth series that peaks at .1 just before the July 1985 collapse. The somewhat obvious point is that estimation will bear more fruit for periods in which the stylised assumptions of the model come closest to capturing reality.

13 A more computationally intensive calculation would involve re-estimating the model for each month in 1994.

14 Aside from Blanco and Garber (1986), plots of these results can also be found in Folkerts-Landau and Ito (1995). 
Table 4

Estimation results 1978:01-1994:12

\begin{tabular}{|c|c|c|c|c|}
\hline & \multicolumn{2}{|c|}{ Unrestricted } & \multicolumn{2}{|c|}{ Restricted } \\
\hline & Estimate & $\begin{array}{c}\text { Standard } \\
\text { error }\end{array}$ & Estimate & $\begin{array}{c}\text { Standard } \\
\text { error }\end{array}$ \\
\hline$b_{1}$ & 1699.59 & 84.1426 & 1699.59 & 84.1426 \\
\hline$b_{2}$ & -0.0002 & 0.0001 & -0.0002 & 0.0001 \\
\hline$b_{3}$ & -0.9731 & 0.0162 & -0.9732 & 0.0162 \\
\hline$b_{4}$ & 2.4516 & 0.1214 & 2.4516 & 0.1214 \\
\hline$b_{5}$ & 25.3996 & 1.1928 & 25.4 & 1.1928 \\
\hline$b_{6}$ & -6.3627 & 1.2522 & -6.3578 & 1.2524 \\
\hline$b_{7}$ & -7.3183 & 0.2538 & -7.3184 & 0.2538 \\
\hline$b_{8}$ & 231.8 & 12.678 & 231.784 & 12.678 \\
\hline$b_{9}$ & 89.2463 & 56.1845 & 4.8821 & 5.0886 \\
\hline$b_{10}$ & 30.0897 & 33.0058 & 0.4228 & 0.5944 \\
\hline$b_{11}$ & -15.131 & 6.298 & -14.06 & 4.6555 \\
\hline$b_{12}$ & 13.2972 & 5.5893 & 13.6374 & 4.5996 \\
\hline$b_{13}$ & 317.653 & 214.364 & 29.6401 & 73.8073 \\
\hline$b_{14}$ & -12.356 & 13.1527 & 0.5915 & 0.8814 \\
\hline$b_{15}$ & -35.543 & 40.754 & -2.2949 & 31.3625 \\
\hline$b_{16}$ & -4.7935 & 2.9836 & -0.1687 & 1.275 \\
\hline$b_{17}$ & -25.257 & 32.729 & 0.1687 & 1.275 \\
\hline$b_{18}$ & 4.9507 & 4.8651 & 0.0079 & 0.0034 \\
\hline$b_{19}$ & -47.625 & 17.799 & -0.0501 & 0.018 \\
\hline$b_{20}$ & -6.2078 & 7.1681 & -0.0577 & 0.0246 \\
\hline$b_{21}$ & 27.1485 & 1.3441 & 27.1485 & 1.3441 \\
\hline$b_{22}$ & -0.0338 & 0.0026 & -0.0338 & 0.0026 \\
\hline$b_{23}$ & 193.825 & 9.5957 & 193.825 & 9.5957 \\
\hline$b_{24}$ & -0.0014 & 0.0004 & -0.0014 & 0.0004 \\
\hline$b_{25}$ & -0.5129 & 0.06 & -0.5129 & 0.06 \\
\hline $\begin{array}{c}\text { Log } \\
\text { likelihood } \\
\end{array}$ & \multicolumn{2}{|c|}{2264.798} & \multicolumn{2}{|c|}{2257.930} \\
\hline $\begin{array}{c}\text { Likelihood } \\
\text { ratio test }\end{array}$ & \multicolumn{4}{|c|}{13.7364} \\
\hline P-value & \multicolumn{4}{|c|}{0.017} \\
\hline
\end{tabular}




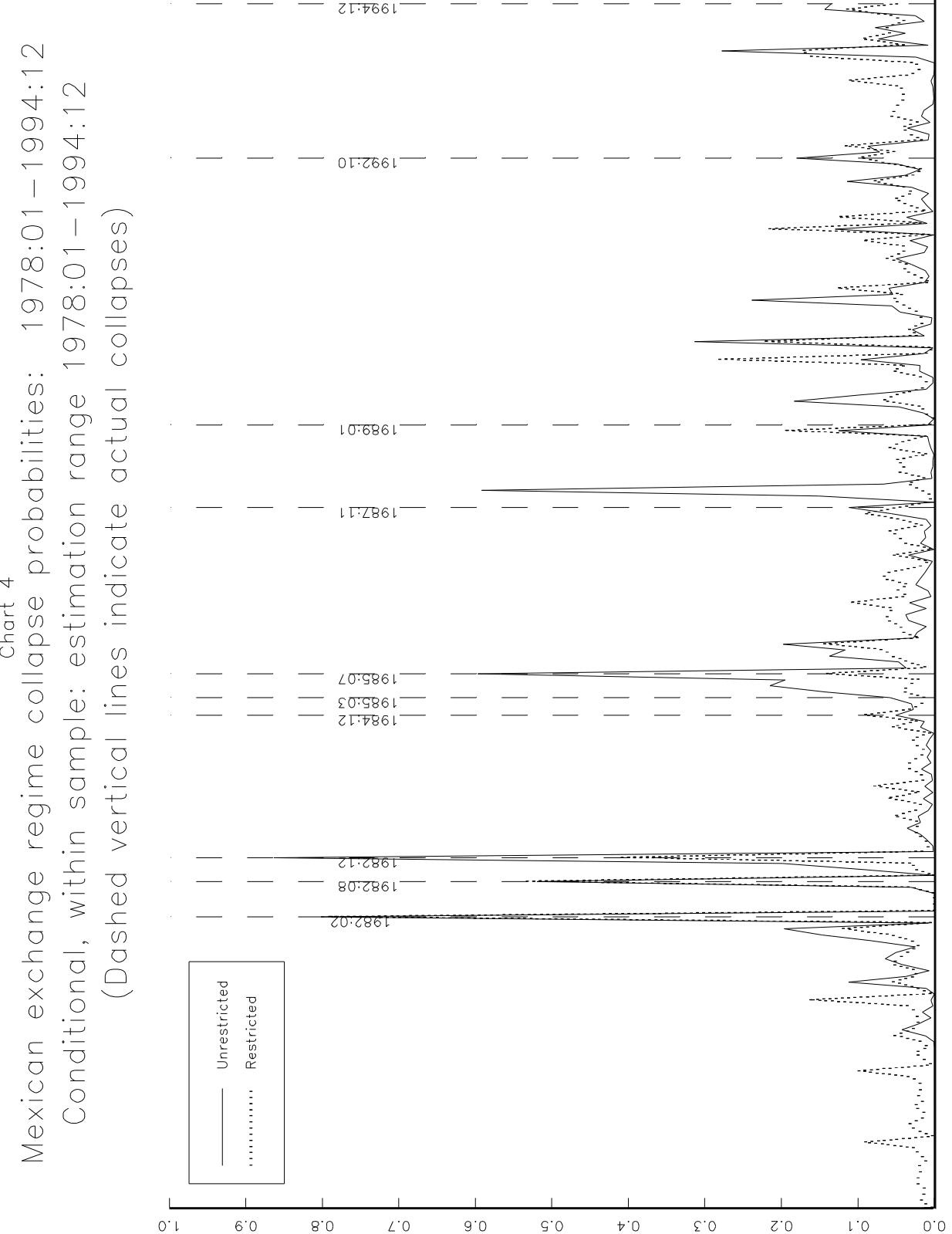




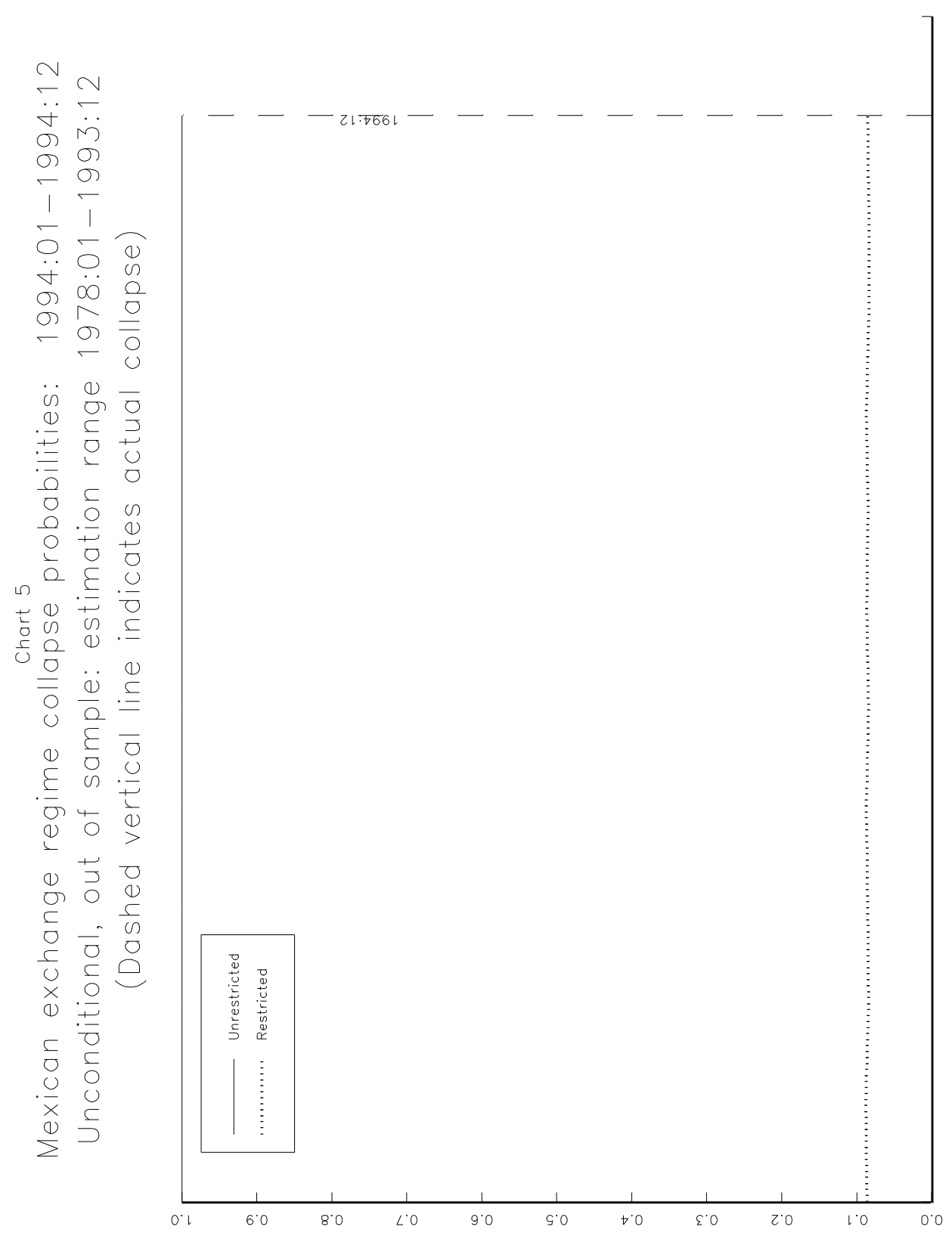




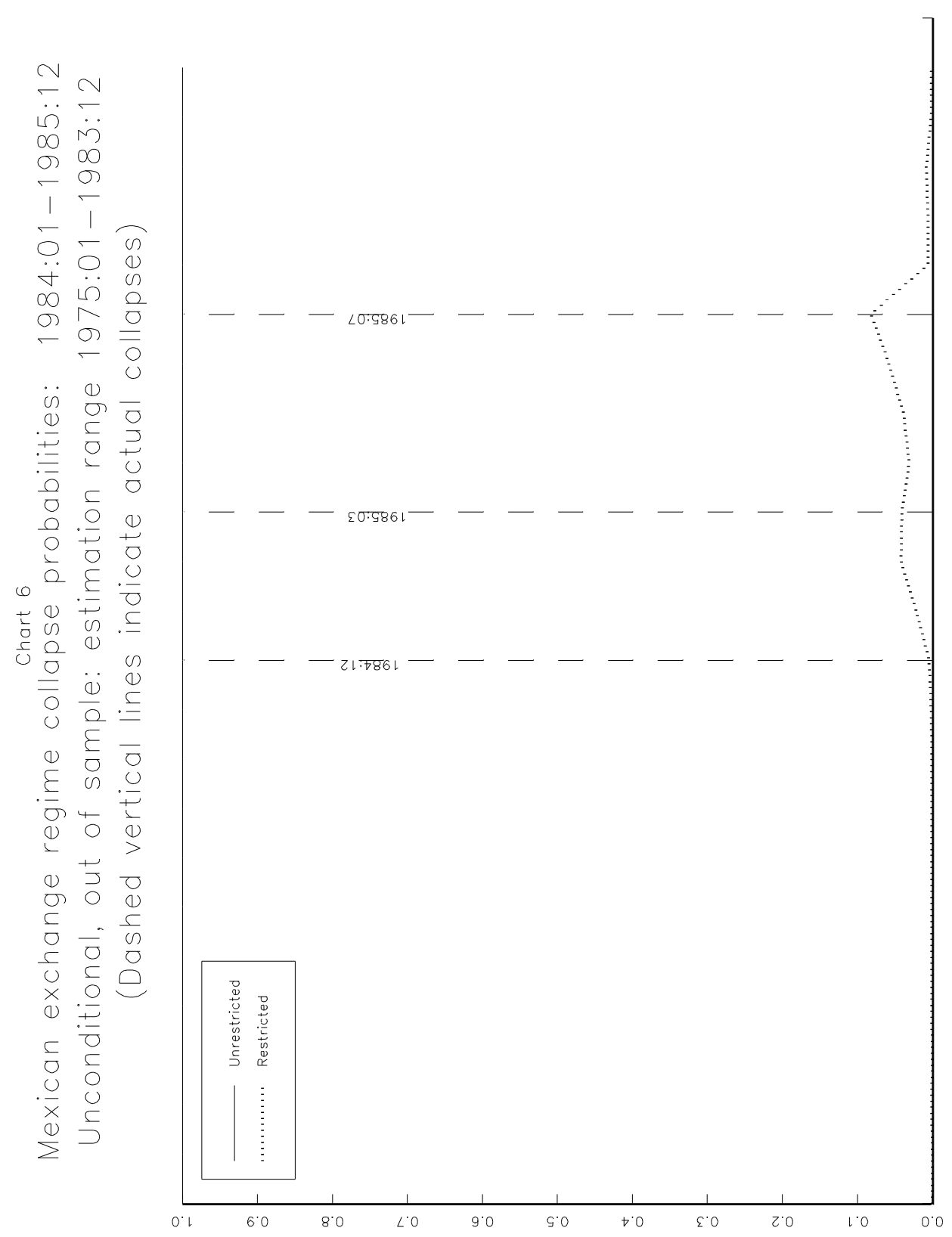




\section{Conclusions}

This paper presents, solves and estimates a speculative attack model of exchange rate crises. The major contributions of the paper are the derivation of a maximum likelihood estimator for the model and its application to Mexico. Empirical results are disappointing in that reduced form estimates are inconsistent with the theoretical assumptions and that model generated collapse probabilities are not consistent with the observed collapses. These negative findings probably relate to the highly stylized model and the nature of the recent Mexican experience. The solution of the model for collapse probabilities and derivation of the maximum likelihood estimator require very simple functional forms that do not capture empirical regularities. Moreover, as mentioned in the introduction, there is good reason to question the applicability of the standard speculative attack paradigm to the events in Mexico in 1994. This questioning is re-enforced by the better performance of the model in predicting the collapse in July 1985. Therefore, it may prove fruitful to apply the techniques of the paper to other countries that better conform to the unsustainable fiscal position envisioned by the standard speculative attack model. 


\section{Appendix: Calculation of conditional probability of collapse}

To evaluate the likelihood function (equation (19) in the text) we need to calculate two terms involving $\operatorname{Pr}\left[c_{t} \mid \theta_{t}, \psi_{t}, \omega_{t}, a_{3} \eta_{t}\right]$. To construct this conditional probability, we appeal to the change of variable technique described in most introductory statistics texts (e.g. Mood, Graybill and Boes (1974)). First, define the random variable $z_{t}$ as

$$
z_{t}=\theta_{t}+\lambda_{3} \psi_{t}+\lambda_{4} \omega_{t}+\lambda_{6} \varepsilon_{t}+\lambda_{7} \eta_{t}
$$

implying from equation (16) that

$$
\mathrm{c}_{t}=\begin{aligned}
& 1 \text { if } z_{t} \geq \bar{s}_{t}-H_{t-1} \\
& 0 \text { if } z_{t}<\bar{s}_{t}-H_{t-1}
\end{aligned}
$$

To calculate $\operatorname{Pr}\left[c_{t}=1 \mid \theta_{t}, \psi_{t}, \omega_{t}, a_{3} \eta_{t}\right]$ and $\operatorname{Pr}\left[c_{t}=0 \mid \theta_{t}, \psi_{t}, \omega_{t}, a_{3} \eta_{t}\right]$ we require

$$
f_{z}\left(z_{t} \mid \theta_{t}, \psi_{t}, \omega_{t}, a_{3} \eta_{t}\right)=\frac{f_{z, \theta, \psi, \omega, a_{3} \eta}\left(z_{t}, \theta_{t}, \psi_{t}, \omega_{t}, a_{3} \eta_{t}\right)}{f_{\theta, \psi, \omega, a_{3} \eta}\left(\theta_{t}, \psi_{t}, \omega_{t}, a_{3} \eta_{t}\right)}
$$

To derive an expression for the numerator we define five new variables and a Jacobian, dropping time subscripts when convenient

$$
\begin{aligned}
& Y_{1}=\theta_{t}+\lambda_{3} \psi_{t}+\lambda_{4} \omega_{t}+\lambda_{6} \varepsilon_{t}+\lambda_{7} \eta_{t}=g_{1}\left(\varepsilon, \theta, \psi, \omega, a_{3} \eta\right) \\
& Y_{2}=\theta_{t}=g_{2}\left(\varepsilon, \theta, \psi, \omega, a_{3} \eta\right) \\
& Y_{3}=\psi_{t}=g_{3}\left(\varepsilon, \theta, \psi, \omega, a_{3} \eta\right) \\
& Y_{4}=\omega_{t}=g_{4}\left(\varepsilon, \theta, \psi, \omega, a_{3} \eta\right) \\
& Y_{5}=a_{3} \eta_{t}=g_{5}\left(\varepsilon, \theta, \psi, \omega, a_{3} \eta\right)
\end{aligned}
$$

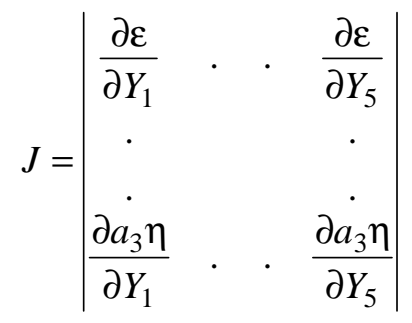


We now can write the numerator of the RHS of (A3) as

$$
\begin{aligned}
f_{z, \theta, \psi, \omega, a_{3} \eta}\left(z_{t}, \theta_{t}, \psi_{t}, \omega_{t}, a_{3} \eta_{t}\right) & =f\left(Y_{1}, Y_{2}, Y_{3}, Y_{4}, Y_{5}\right) \\
& =|J| f_{\varepsilon, \theta, \psi, \omega, a_{3} \eta}\left(g_{1}^{-1}\left(Y_{1}, Y_{2}, Y_{3}, Y_{4}, Y_{5}\right), ., . . g_{5}^{-1}\left(Y_{1}, Y_{2}, Y_{3}, Y_{4}, Y_{5}\right)\right) \\
& =|J| f_{\varepsilon}\left(g_{1}^{-1}\left(Y_{1}, Y_{2}, Y_{3}, Y_{4}, Y_{5}\right)\right) ., ., . f_{a_{3} \eta}\left(g_{5}^{-1}\left(Y_{1}, Y_{2}, Y_{3}, Y_{4}, Y_{5}\right)\right)
\end{aligned}
$$

where the last equality in equation (A4) results from the assumed independence of $\varepsilon, \theta, \psi, \omega$, and $\eta$. Using the result from equation (A4) and again the assumption of independence, equation (A3) can be written as

$$
f_{z}\left(z_{t} \mid \theta_{t}, \Psi_{t}, \omega_{t}, a_{3} \eta_{t}\right)=\frac{|J| f_{\varepsilon}\left(g_{1}^{-1}\left(Y_{1}, Y_{2}, Y_{3}, Y_{4}, Y_{5}\right)\right) . ., . . f_{a_{3} \eta}\left(g_{5}^{-1}\left(Y_{1}, Y_{2}, Y_{3}, Y_{4}, Y_{5}\right)\right)}{f_{\theta}\left(\theta_{t}\right) . . . . . f_{a_{3} \eta}\left(a_{3} \eta_{t}\right)}
$$

Noting that $Y_{2}=\theta, Y_{3}=\psi, Y_{4}=\omega$ and $Y_{5}=a_{3} \eta$, and calculating the Jacobian, equation (A5) simplifies to

$$
f_{z}\left(z_{t} \mid \theta_{t}, \psi_{t}, \omega_{t}, a_{3} \eta_{t}\right)=\frac{1}{\lambda_{6}} f_{\varepsilon}\left(g_{1}^{-1}\left(Y_{1}, Y_{2}, Y_{3}, Y_{4}, Y_{5}\right)\right)
$$

Using the assumption that $\varepsilon$ is normally distributed yields

$$
f_{z}\left(z_{t} \mid \theta_{t}, \psi_{t}, \omega_{t}, a_{3} \eta_{t}\right)=\frac{1}{\lambda_{6}} \frac{1}{(2 \pi)^{5}} \frac{1}{\sigma_{\varepsilon}} e^{-\left(\frac{\left(z_{t}-\theta_{t}-\lambda_{3} \psi_{t}-\lambda_{4} \omega_{t}-\lambda_{7} \eta_{t}\right)}{\lambda_{6} \sigma_{\varepsilon}}\right)^{2} / 2}
$$

With equation (A7) it is now possible to calculate

$$
\begin{aligned}
\operatorname{Pr}\left[c_{t}\right. & \left.=1 \mid \theta_{t}, \psi_{t}, \omega_{t}, a_{3} \eta_{t}\right]=\operatorname{Pr}\left[z_{t} \geq \bar{s}_{t}-H_{t-1} \mid \theta_{t}, \psi_{t}, \omega_{t}, a_{3} \eta_{t}\right] \\
& =1-\int_{-\infty}^{\bar{s}_{t}-H_{t-1}} \frac{1}{\lambda_{6}} \frac{1}{(2 \pi)^{.5}} \frac{1}{\sigma_{\varepsilon}} e^{-\left(\frac{\left(z_{t}-\theta_{t}-\lambda_{3} \psi_{t}-\lambda_{4} \omega_{t}-\lambda_{7} \eta_{t}\right)}{\lambda_{6} \sigma_{\varepsilon}}\right)^{2} / 2} \\
& =1-\Phi\left[\frac{\left(\bar{s}_{t}-H_{t-1}-\theta_{t}-\lambda_{3} \psi_{t}-\lambda_{4} \omega_{t}-\lambda_{7} \eta_{t}\right)}{\lambda_{6} \sigma_{\varepsilon}}\right] \\
& =\Phi\left[\frac{-\left(\bar{s}_{t}-H_{t-1}-\theta_{t}-\lambda_{3} \psi_{t}-\lambda_{4} \omega_{t}-\lambda_{7} \eta_{t}\right)}{\lambda_{6} \sigma_{\varepsilon}}\right]
\end{aligned}
$$

In a similar fashion, we obtain 
(A9) $\quad \operatorname{Pr}\left[c_{t}=0 \mid \theta_{t}, \psi_{t}, \omega_{t}, a_{3} \eta_{t}\right]=\Phi\left[\frac{\left(\bar{s}_{t}-H_{t-1}-\theta_{t}-\lambda_{3} \psi_{t}-\lambda_{4} \omega_{t}-\lambda_{7} \eta_{t}\right)}{\lambda_{6} \sigma_{\varepsilon}}\right]$

Finally, equations (A8) and (A9) can be used to replace the last term on the RHS of equation (19) as

(A10)

$$
\begin{aligned}
& \Phi\left[\left(\frac{\bar{s}_{t}-H_{t-1}-\theta_{t}-\lambda_{3} \psi_{t}-\lambda_{4} \omega_{t}-\lambda_{7} \eta_{t}}{\lambda_{6} \sigma_{\varepsilon}}\right)\left(1-2 c_{t}\right)\right]= \\
& c_{t} \ln \operatorname{Pr}\left[c_{t}=1 \mid \theta_{t}, \psi_{t}, \omega_{t}, a_{3} \eta_{t}\right]+\left(1-c_{t}\right) \ln \operatorname{Pr}\left[c_{t}=0 \mid \theta_{t}, \psi_{t}, \omega_{t}, a_{3} \eta_{t}\right]
\end{aligned}
$$

This is the result used in equation (20). 


\section{References}

Agénor, Pierre-Richard, Jagdeep S. Bhandari and Robert P. Flood (1992): "Speculative Attacks and Models of Balance of Payments Crises". International Monetary Fund Staff Papers, 39 (2), June, pp. 357-394.

Banco de Mexico (1995): Report on Monetary Policy, January.

Blanco, Herminio and Peter M. Garber (1986): "Recurrent Devaluation and Speculative Attacks on the Mexican Peso". Journal of Political Economy, 94(1), February, pp. 148-166.

Cumby, Robert E. and Sweder Van Wijnbergen (1989): "Financial Policy and Speculative Runs with a Crawling Peg: Argentina 1979-1981". Journal of International Economics, 27, August, pp. 111-127.

Dornbusch, Rudiger and Alejandro Werner (1994): "Mexico: Stabilization, Reform, and No Growth". Brookings Papers on Economic Activity, 1, pp. 253-97.

Flood, Robert P. and Peter M. Garber (1994): "Collapsing Exchange Rate Regimes: Some Linear Examples". Journal of International Economics, 17 (1-2), pp. 1-13.

Flood, Robert P., Peter M. Garber and Charles Kramer (1995): "Collapsing Exchange Rate Regimes: Another Linear Example". NBER Working Paper No. 5318, National Bureau of Economic Research, October.

Flood, Robert P. and Robert J. Hodrick (1986): "Real Aspects of Exchange Rate Regime Choice with Collapsing Fixed Rates". Journal of International Economics, 21 (3-4), November, pp. 215-32.

Folkerts-Landau, David and Takatoshi Ito (1995): International Capital Markets: Developments, Prospects and Policy Issues. International Monetary Fund, August.

Gerlach, Stefan and Frank Smets (1994): "Contagious Speculative Attacks". Working Paper No. 22, Bank for International Settlements, September.

Goldberg, Linda S. (1991): "Collapsing Exchange Rate Regimes: Shocks and Biases". Journal of International Money and Finance, 10 (2), June, pp. 252-263.

Goldberg, Linda S. (1994): "Predicting Exchange Rate Crises: Mexico Revisited". Journal of International Economics, 36 (3-4), May, pp. 413-430.

International Monetary Fund: Annual Report on Exchange Arrangements and Exchange Restrictions. Various issues.

Kamin, Steven B. and John H. Rogers (1996): "Monetary Policy in the End-Game to Exchange-Rate Based Stabilizations: The Case of Mexico". International Finance Discussion Paper No. 540, Board of Governors of the Federal Reserve System, February.

Melick, William R. (1987): "Collapsing Exchange Rate Regimes Under Governmental Optimization". Ph.D. dissertation (unpublished), Ohio State University.

Miller, Victoria (1996): "Speculative Currency Attacks With Endogenously Induced Commercial Bank Crises". Journal of International Money and Finance, 15 (3), June, pp. 383-403. 
Mood, Alexander M., Franklin A. Graybill and Duane C. Boes (1974): Introduction to the Theory of Statistics, 3rd Edition. McGraw-Hill (New York).

Obstfeld, Maurice (1986a): "Speculative Attack and the External Constraint in a Maximizing Model of the Balance of Payments". Canadian Journal of Economics, 19 (1), February, pp. 1-22.

Obstfeld, Maurice (1986b): "Rational and Self-Fulfilling Balance-of-Payments Crises". American Economic Review, 76 (1), March, pp. 72-81.

Obstfeld, Maurice (1996): "Models of Currency Crises With Self-Fulfilling Features". Discussion Paper No. 1315, Centre for Economic Policy Research, January.

Ötker, Inci and Ceyla Pazarbasioglu (1995): "Speculative Attacks and Currency Crises: The Mexican Experience". Working Paper WP/95/112, International Monetary Fund, November.

Organisation for Economic Co-operation and Development (1995): OECD Economic Surveys - Mexico.

Penati, Alessandro, and George Pennacchi (1989): "Optimal Portfolio Choice and the Collapse of a Fixed-Exchange Rate Regime". Journal of International Economics, 27 (1-2), August, pp. 1-24. 